\title{
INICIACIÓN CRISTIANA Y PASTORAL VOCACIONAL
}

AURELIO GARCÍA MACÍAS 1

DOI: https://doi.org/10.52039/seminarios.v54i187.549

Nos encontramos en este trabajo con la clave de la pastoral y de la pastoral de las vocaciones: la sintonía eucarística. El autor va recorriendo los sacramentos de iniciación desde esta clave y nos abre horizontes de reflexión y de trabajo pastoral. Algún acento a destacar. El proceso de la pastoral de las vocaciones está inserto en el proceso de la iniciación cristiana. Es importante considerar los pasos, las etapas, los contenidos y los signos, la mistagogía, para hacer pastoral vocacional. Por último el autor dedica unas buenas páginas a profundizar en la importancia de la celebración eucarística en la formación sacerdotal y en la vivencia de la vocación al presbiterado.

Es evidente que todo proyecto de pastoral vocacional está íntimamente relacionado con el proceso de la iniciación cristiana. La llamada a un especial ministerio eclesial o a una consagración religiosa presupone la llamada básica a la vocación cristiana que Dios hace a todo creyente desde el bautismo. Por tanto, la respuesta a la universal vocación bautismal de todo cristiano es el presupuesto y el cimiento de toda pastoral vocacional. Sin cristianos, no hay vocaciones; sin vida cristiana, no hay pastoral vocacional.

En este único proceso vital de la existencia cristiana podemos distinguir una doble iniciación vocacional: "cristiana" y "ministerial o carismática". La primera es respuesta a la básica y común vocación bautismal de todo

\footnotetext{
1 El autor es presbítero de la Diócesis de Valladolid, nacido en 1965. Tras sus estudios en el Seminario Diocesano de la capital castellana, obtuvo la licenciatura en Filosofía y Ciencias de la Educación en la Universidad de Salamanca, y el doctorado en Liturgia en el Pontificio Instituto Litúrgico "San Anselmo" de Roma. Es profesor en Valladolid, Barcelona y Madrid; consultor del Secretariado de la Comisión Episcopal de Liturgia de la Conferencia Episcopal Española; y Presidente de la Asociación Española de Profesores de Liturgia. Es Delegado Diocesano de Liturgia y párroco de las Parroquias del Santísimo Salvador y de Santiago Apóstol de Valladolid. Cuenta con numerosas publicaciones en revistas de tema litúrgico.
} 


\section{"INICIACIÓN CRISTIANA Y PV", AURELIO GARCÍA}

cristiano, y requiere la celebración de los sacramentos de la iniciación cristiana: Bautismo, Confirmación y Eucaristía. La segunda supone una iniciación y preparación para responder a la vocación específica que pide el Señor en un ministerio o carisma concreto para edificar su Iglesia y servir al mundo. La pastoral vocacional ayuda a descubrir esta llamada particular del Señor y encamina los pasos del fiel hasta el lugar idóneo donde madurar su respuesta y prepararse para la misión confiada. En ambos momentos del único proceso vital del cristiano, la Eucaristía ocupa un lugar central y referencial para vivir la existencia cristiana como una respuesta vocacional.

\section{Los sacramentos de la iniciación y la vocación cristiana}

La reflexión actual de la Iglesia, preocupada en estos últimos años por la transmisión de la fe en una cultura cada vez más indiferente hacia lo religioso, ha centrado su atención en el proceso de la iniciación cristiana. Fruto de estas reflexiones es el documento publicado hace algunos años por la Conferencia Episcopal Española en el que aporta también algunas clarificaciones doctrinales y orientaciones prácticas.

Definía la iniciación cristiana como "la inserción de un candidato en el misterio de Cristo, muerto y resucitado, y en la Iglesia por medio de la fe y de los sacramentos". 2 La iniciación cristiana es, pues, el tiempo y el camino necesarios de preparación personal para adherirse a Jesucristo mediante la fe y la vida, que culmina en la celebración de los sacramentos del bautismo, de la Confirmación y de la Eucaristía. El objetivo, por tanto, de este proceso es "hacer cristianos", es decir, introducir a los hombres en el misterio de Cristo y de la Iglesia; conducirlos al íntimo conocimiento del misterio de la salvación e iniciar en ellos un estilo de vida propio del Evangelio.

Desde la época apostólica la Iglesia ha seguido un mismo proceso de iniciación cristiana: el catecumenado, que ha perdurado hasta hoy como el camino ejemplar para iniciar a los adultos en la fe y ha sido recuperado por el Concilio Vaticano II en el Ritual de la Iniciación Cristiana de Adultos. Se trata de un proceso con diversas etapas; un proceso unitario y gradual. Comienza con el anuncio de Jesucristo muerto y resucitado, ante el que caben dos posibles respuestas: el no de aquellos que lo rechazan, y el sí

2 CONFERENCIA EPISCOPAL ESPAÑOLA, La iniciación cristiana. Reflexiones y Orientaciones (=IC), Madrid 1998, nº 19. 


\section{"INICIACIÓN CRISTIANA Y PV", AURELIO GARCÍA}

de quienes quieren conocer a Jesucristo. Quienes responden afirmativamente se les invita a entrar en el catecumenado, es decir, un tiempo de formación teórica y práctica, doctrinal y moral para comprender el misterio de Jesucristo y vivir libremente conforme a él. Es un periodo que puede durar varios años, acompañados por la comunidad cristiana, que le acoge y ora por él; hasta que culmina en la celebración de los tres sacramentos de la iniciación cristiana en la gran noche sacramental de la Vigilia pascual.

Este es el proceso habitual de los adultos que piden ser iniciados en la fe cristiana e incorporados a la Iglesia. Sin embargo, la praxis pastoral de la Iglesia desarrolló también otra forma alternativa para la iniciación cristiana de los párvulos. Cuando la familia cristiana aseguraba la formación cristiana de sus hijos, la Iglesia los bautizaba siendo niños y posponía la formación doctrinal y moral del niño, alternando posteriormente los sacramentos de la Confirmación y de la Eucaristía. Esta es la praxis pastoral habitual entre nosotros hasta el momento. Sin embargo, ambas formas son válidas y actuales para la iniciación cristiana, bien sean niños o adultos.

En este proceso de iniciación cristiana hay dos dimensiones fundamentales y necesarias para la recta y adecuada formación integral del catecúmeno: la catequesis y la liturgia. La catequesis es una formación orgánica y sistemática de la fe, centrada en lo nuclear de la experiencia cristiana, dirigida por los catequistas que son transmisores y garantes de la Iglesia y delegados de la comunidad cristiana, que acoge y forma a los catecúmenos. La catequesis doctrinal y experiencial es inseparable de la celebración litúrgica y de la oración. Por eso, la Iglesia acompaña este proceso con una serie de celebraciones litúrgicas que, unidas a la acción catequética, suponen momentos eclesiales de encuentro de los catecúmenos con Dios en Jesucristo, y de ellos depende, en gran parte, el fruto espiritual de este itinerario y hasta incluso el sentido mismo de su vida. ${ }^{3}$ Además, las celebraciones litúrgicas "contribuyen a la formación de la fe de los fieles, avivando y nutriendo esa misma fe, creando un clima adecuado de comprensión de los textos y de los signos y, sobre todo, ayudándoles a vivir hoy el acontecimiento de la salvación". ${ }^{4}$

${ }^{3}$ IC, $n^{\circ} 45$ : "del esmero que se ponga en hacer de ellos verdaderos momentos eclesiales del encuentro salvador con Dios en Jesucristo, unidos a la acción catequética, dependerá en gran medida el fruto espiritual de todo el itinerario de la iniciación, y aún el sentido mismo de toda la vida cristiana, por la iniciación en el lenguaje bíblico y litúrgico, por la centralidad de la Eucaristía dominical, por el acercamiento al sacramento de la Penitencia".

4 IC, $\mathrm{n}^{\circ} 53$ 


\section{"INICIACIÓN CRISTIANA Y PV", AURELIO GARCÍA}

Por eso, la liturgia inspira una peculiar forma de catequesis, llamada mistagógica, que "pretende introducir en el misterio de Cristo procediendo de lo visible a lo invisible, del signo a lo significado, de los sacramentos a los misterios". 5 Esta catequesis consiste en una explicación de los ritos, símbolos y gestos de la celebración, a la vez que trata de inculcar en los candidatos a los sacramentos las actitudes internas de conversión y de fe que hagan más fructuosa su participación. Esta catequesis es esencialmente bíblica y litúrgica, y expone la continuidad entre los acontecimientos de la historia de la salvación y los signos sacramentales de la Iglesia". 6 La mistagogía es el mejor camino para que los fieles se apropien del sentido auténtico de la liturgia, que está hecha de signos, palabras, gestos, posturas, silencios y movimientos de profundo significado. Si no se comprende este sentido no se comprende la celebración de la fe.

El tono litúrgico de este artículo me invita a detenerme en las acciones o elementos centrales del proceso de la iniciación cristiana: la celebración de los sacramentos. No son momentos pedagógicos sino sacramentales, fuente y cima del proceso catecumental, donde se realiza la vinculación de los catecúmenos con Jesucristo y se les comunica la salvación. Me gustaría comentar algunos aspectos que denotan la dimensión vocacional de estos tres sacramentos que podríamos denominar "el gran sacramento de la iniciación cristiana".

\subsection{El Bautismo: el Padre llama a la vida}

Si existimos es porque Dios ha pensado en nosotros; y cada uno es fruto del amor creador y de la voluntad eficiente de Dios Padre. Él nos llama a la vida; y el hombre existe porque es pensado y amado por Dios. La vida del hombre es un misterio de predilección y gratuidad, una vocación a la vida, una vocación a la vida eterna. Esto es lo que se celebra en el Bautismo. En él, Dios bendice el fruto del amor humano para hacerlo plenamente hijo suyo, para llamarlo a vivir como hijo de Dios. El bautismo inicia la vida cristiana comprendida como filiación divina, que vive en responsabilidad la relación filial con Dios Padre y la relación fraterna con la gran familia de los hijos de Dios. La fidelidad al bautismo impulsa a plantear la vida como discernimiento y respuesta a la voluntad de Dios en la propia vida.

El sacramento del Bautismo es, por tanto, el fundamento de toda la vida cristiana, el principio y comienzo que tiende a conseguir la plenitud de la vida

\footnotetext{
5 IC, $n^{\circ} 49$

6 IC, $\mathrm{n}^{\circ} 48$
} 


\section{"INICIACIÓN CRISTIANA Y PV", AURELIO GARCÍA}

en Cristo. En él somos regenerados como hijos de Dios, injertados en el misterio pascual de Jesucristo, incorporados a la Iglesia y hechos partícipes de su misión. Hay tres gestos muy significativos en la liturgia bautismal, que recuerdan esta dimensión vocacional a la existencia cristiana, como hijos de Dios, injertados en Jesucristo, para vivir en el Espíritu.

En primer lugar, tras la infusión o inmersión en el agua bendecida, el celebrante unge la cabeza de los bautizandos con el Santo Crisma diciendo las siguientes palabras: Dios todopoderoso, Padre de nuestro Señor Jesucristo, que os ha liberado del pecado y dado nueva vida por el agua y el Espíritu Santo, os consagre con el crisma de la salvación para que entréis a formar parte de su pueblo y seáis para siempre miembros de Cristo, sacerdote, profeta y rey. La crismación subraya que el bautismo es el sacramento de la "nueva vida", de la "regeneración", que purifica del pecado para vivir como miembros del Cuerpo de Cristo y formando parte de su pueblo. La crismación subraya la dignidad de todo cristiano, su vocación principal: participar de la dignidad y misión sacerdotal, profética y real del mismo Cristo. Es el signo de los "marcados en Cristo", que forman parte de su pueblo, la Iglesia.

Tras este signo, el celebrante impone, en segundo lugar, la vestidura blanca a los recién bautizados diciendo: "sois ya nueva criatura y habéis sido revestidos de Cristo. Esta vestidura blanca sea signo de vuestra dignidad de cristianos. Ayudados por la palabra y el ejemplo de los vuestros, conservadla sin mancha hasta la vida eterna. Retomando la metáfora paulina de la "re-creación" y "re-nacimiento" en Jesucristo, la vestidura blanca recuerda la purificación del pecado y la dignidad de quien está unido a Cristo. Ser cristiano significa estar revestido de Cristo, es decir, ser y aparecer como Cristo. Estas palabras hacen una constatación presente ("sois ya..."), pero plantean también un reto futuro que implica toda la vida ("conservadla sin mancha hasta la vida eterna").

Finalmente, el celebrante entrega un cirio encendido al padre o padrino diciendo: Recibid la luz de Cristo. A vosotros, padres y padrinos, se os confía acrecentar esta luz. Que vuestros hijos, iluminados por Cristo, caminen siempre como hijos de la luz. Y perseverando en la fe, puedan salir con todos los Santos al encuentro del Señor. La vela se ha encendido en la llama del Cirio pascual. Todo un simbolismo. Hasta ahora esa vela estaba intacta, totalmente nueva y sin servir para lo que ha sido hecha. A partir de este momento, al tomar el fuego del Cirio pascual, -signo de Cristo Resucitado-, comienza a iluminar y al mismo tiempo a desgastarse. Es un simbolismo de la vida cristiana. El bautizado recibe de Cristo la luz de la fe, que han de cuidar los padres y padrinos; y vivir como "hijo de la luz", es decir, unido a Cristo y como Cristo perseverando en la fe hasta el 


\section{"INICIACIÓN CRISTIANA Y PV", AURELIO GARCÍA}

final. Seguidamente se ora en común la oración dominical que, unidos a Jesucristo, dirigimos al Padre como hijos suyos.

Estos tres gestos litúrgicos son para el bautizado un programa de vida cristiana, una llamada a no olvidar los propósitos manifestados en el bautismo, un misterio sacramental que determina toda vocación cristiana desde el inicio hasta el final de la vida.

\subsection{La Confirmación: El Espíritu llama al testimonio}

Jesús inicia su vida pública siendo bautizado por su primo Juan en el río Jordán. Su bautismo es el final de sus años de anonimato en Nazaret y el comienzo de su ministerio mesiánico en Israel. El hermoso relato evangélico describe que descendió el Espíritu Santo sobre Jesús, en forma de paloma. Poco tiempo después, en su visita a la sinagoga de Nazaret, el mismo Jesús hace referencia a este pasaje cuando afirma: "El Espíritu del Señor está sobre mí... porque él me ha ungido... me ha enviado" (Lc 4,18). Son palabras clave para comprender la persona y el ministerio de Jesucristo. Se autodefine como el "ungido" y el "enviado". Y entre ambos vocablos hay una estrecha concomitancia. Jesús es ungido con la fuerza del Espíritu Santo para ser enviado. Esta es la lógica de tal unción. Aunque era Hijo de Dios, antes de inaugurar su ministerio mesiánico es ungido con la fuerza del Espíritu para realizar la misión encomendada por el Padre y cumplir su voluntad. Jesús es el Mesías, es decir, el Cristo; es decir, el Ungido, para ser enviado.

Los Apóstoles, tras la experiencia de la resurrección del Señor, viven el acontecimiento de Pentecostés en el que reciben el don del Espíritu Santo, que desciende sobre ellos en forma de fuego. La fuerza del Espíritu recibido les impulsa a superar el miedo y comenzar en ese mismo día la misión encomendada por el mismo Cristo. También los Apóstoles son marcados con el don del Espíritu para ser enviados a prolongar la misión de Jesucristo.

El cristiano, tras el sacramento del Bautismo, recibe el don del Espíritu Santo para ser fortalecido con la gracia divina y poder realizar la misión que el Padre le encomienda en su vida. Este es el sentido del sacramento de la Confirmación: "Dentro del conjunto de la Iniciación cristiana, el sacramento del don del Espíritu es la confirmación del Bautismo, que pone de manifiesto la presencia y la acción del Espíritu Santo en la Iglesia y en los bautizados... a los bautizados los une más íntimamente a la Iglesia y los enriquece con una fortaleza especial del Espíritu Santo".7

7 IC, $\mathrm{n}^{\circ} 55$ 


\section{"INICIACIÓN CRISTIANA Y PV", AURELIO GARCÍA}

En muchas explicaciones actuales de este sacramento predomina una cierta confusión, que resalta únicamente la acción activa del candidato. Parece que se prepara a muchos jóvenes para que sean ellos quienes "se confirmen" en la fe llegados a una cierta mayoría de edad. Si en el bautismo fueron los padres y padrinos quienes renunciaron al pecado y profesaron la fe, asumiendo responsablemente la formación cristiana de su hijo; ahora es el joven quien quiere renunciar y profesar adquiriendo, a veces, un protagonismo excesivo en la celebración y reduciendo este sacramento a una especie de profesión pública de su fe. ${ }^{8}$ Sin embargo, los textos del Ritual de la Confirmación enseñan que lo principal de este sacramento es el don del Espíritu Santo, que fortalece al confirmado y le capacita para su misión y vocación cristiana. También él es un ungido de Dios, al igual que Jesús, los apóstoles y todos los cristianos de la historia, para ser enviado y realizar su vocación cristiana.

El sacramento de la Confirmación no puede reducirse a una nueva profesión de fe pública del confirmando, o a un compromiso más grande, ni siquiera a un suplemento facultativo; es un don de Dios que perfecciona al cristiano, es el don del Espíritu que unge al candidato para ser enviado como apóstol y poder realizar la misión que el Señor le encomienda en la Iglesia y en el mundo. ¡Qué bien está expuesto en la eucología de la misma celebración del sacramento! Me gustaría comentar, a modo de ejemplo, tres oraciones representativas de esta celebración.

En primer lugar, la oración colecta: Cumple, Señor, en nosotros tu promesa: Derrama tu Espíritu santo para que nos haga ante el mundo testigos valientes del Evangelio de Jesucristo, que vive y reina contigo. Señala los elementos anteriormente mencionados: "derrama tu Espíritu Santo" (don, unción) y "nos haga ante el mundo testigos valientes del Evangelio" (misión, envío). La recepción del Espíritu transforma a quien lo recibe en testigo valiente de Jesucristo en el mundo.

La oración sobre las ofrendas subraya la misma lógica del "don" para la "misión": Recibe, Señor, las ofrendas de estos hijos tuyos, configurados hoy más perfectamente con Cristo, que con su muerte nos mereció el don del Espíritu, y concédeles que la participación en la Eucaristía, memorial de la pascua del Señor, les impulse a dar testimonio de Jesucristo, tu Hijo,

\footnotetext{
8 Habría mucho que decir de la insana proliferación de textos de renuncia y profesión de fe que se inventan en muchas celebraciones resultando ingenuos y ficticios en la mayor parte de su contenido. El Ritual de la Confirmación propone las preguntas básicas de la tradición cristiana, vinculando este momento con las mismas preguntas hechas en el bautismo y vinculando estos dos momentos del mismo proceso de la iniciación cristiana.
} 


\section{"INICIACIÓN CRISTIANA Y PV", AURELIO GARCÍA}

que vive y reina por los siglos de los siglos. La unción del Espíritu y de la Eucaristía configuran a quien lo recibe más perfectamente a Cristo y le impulsan a dar testimonio de Jesucristo.

La oración después de la comunión repite el mismo esquema: Dios todopoderoso, mira con bondad a los que has enriquecido con los dones de tu Espíritu y alimentado con el Cuerpo y Sangre de tu Hijo; concédeles también vivir en el amor, plenitud de tu ley, manifestar la libertad gloriosa de los hijos de Dios y, por la santidad de su vida, cumplir su misión profética en el mundo. El don del Espíritu y de la Eucaristía santifican la vida del creyente para vivir su misión profética en el corazón del mundo. Primero es el don del Espíritu que capacita al creyente para su misión cristiana en el mundo. Así se subraya también en la exhortación que hace el Obispo antes de imponer las manos sobre los candidatos al sacramento de la Confirmación: Oremos, hermanos, a Dios Padre todopoderoso y pidámosle que derrame el Espíritu Santo sobre estos hijos de adopción que renacieron ya a la vida eterna en el Bautismo, para que los fortalezca con la abundancia de sus dones, los consagre con su unción espiritual y haga de ellos imagen perfecta de Jesucristo.

Esta lógica sacramental revela también una lógica vocacional. Primero es la llamada, el don de Dios como capacitación existencial para una misión y posteriormente la disponibilidad de quien lo recibe, que es la respuesta del sí al don recibido por Dios. Ante las palabras del Obispo en el gesto de la crismación ("Recibe por esta señal el don del Espíritu Santo"), el confirmando responde únicamente "Amén", como expresión de su respuesta disponible al don recibido. Tras el don del Espíritu, el confirmado confirma y renueva su fidelidad vocacional como hijo de Dios, en la Iglesia, para dar testimonio de Jesucristo con su vida y con su palabra, realizando la misión concreta que Dios tiene para cada uno.

\subsection{La Eucaristía: El Hijo llama al seguimiento}

"El tercer sacramento de la Iniciación cristiana es la Eucaristía; en ella la iniciación alcanza su culminación. En efecto, los que han sido elevados a la dignidad del sacerdocio real por el Bautismo y configurados más profundamente con Cristo por la Confirmación, participan por medio de la Eucaristía con toda la comunidad en el sacrificio mismo del Señor. La Eucaristía significa y realiza la comunión de vida con Dios y la unidad de la Iglesia, es pregustación de la vida eterna y compendio y suma de nuestra $f e " .9$ Estas palabras del documento "La Iniciación cristiana. Reflexiones y

9 IC, $n^{\circ} 57$. 


\section{SEMINARIOS - AÑO 2008 - NO 187 \\ "INICIACIÓN CRISTIANA Y PV", AURELIO GARCÍA}

orientaciones", anteriormente citado, sintetizan los elementos esenciales de este sacramento que culmina el proceso de la iniciación cristiana. La particularidad de este sacramento es que el fiel participa plenamente del sacrifico mismo de Jesucristo y entra en comunión vital con Dios y con su Iglesia. La Eucaristía significa y realiza la comunión de vida con Dios. Este es el valor de la comunión sacramental del Cuerpo y de la Sangre de Cristo. Como dice el Prefacio II de la Santísima Eucaristía: Con este sacramento alimentas y santificas a tus fieles, para que su misma fe ilumine y su mismo amor congregue a todos los hombres que habitan un mismo mundo. Así, pues, nos reunimos en torno a la mesa de este sacramento admirable para que la abundancia de tu gracia nos lleve a poseer la vida celestial. Quien participa del misterio sacramental de la Eucaristía se alimenta del mismo Cristo, y la recepción de los dones eucarísticos es santificación de quien lo recibe para vivir como Él. La Eucaristía se convierte, de este modo, en el sustento espiritual del fiel y del pueblo peregrinos por esta tierra hasta la consumación del tiempo.

Es necesaria una esmerada educación litúrgica en el proceso de la iniciación cristiana que descubra y prepare a los creyentes para comprender y vivir el insondable misterio eucarístico. ${ }^{10}$ Porque la Eucaristía es también experiencia viva del don de Dios y escuela de la respuesta a su llamada. En efecto, toda celebración litúrgica, y sobre todo la eucarística, nos descubre el verdadero rostro de Dios; nos pone en comunicación con el misterio de la Pascua, o sea, con la "hora" por la que Jesús vino al mundo y hacia la que se encaminó libre y voluntariamente en obediencia a la llamada del Padre (cf. Jn 13,1); nos manifiesta el rostro de la Iglesia como pueblo de sacerdotes y comunidad bien compacta en la variedad y complementariedad de los carismas y vocaciones". 11

El Señor Jesús nos llama a vivir y actuar como Él: a vivir su misma relación de trato con el Padre y con los hombres, y a actuar haciendo de la propia vida una misión de entrega a los demás. Esta actitud oblativa caracteriza su misión de amor, que alcanza su culmen en la cruz: " No hay amor más grande que dar la vida por los amigos " (Jn 15,13). Todo discípulo y todo cristiano está llamado a reproducir y revivir esta misión de

10 JUAN PABLO II, Exhortación Apostólica postsinodal "Pastores dabo vobis" (=PDV), Città del Vaticano 1992, $\mathrm{n}^{\circ}$ 48: El culmen de la oración cristiana es la Eucaristía, que a su vez es "la cumbre y fuente" de los Sacramentos y de la Liturgia de las Horas. Para la formación espiritual de todo cristiano, y en especial de todo sacerdote, es muy necesaria la educación litúrgica, en el sentido pleno de una inserción vital en el misterio pascual de Jesucristo muerto y resucitado, presente y operante en los sacramentos de la Iglesia.

11 PDV 38 


\section{"INICIACIÓN CRISTIANA Y PV", AURELIO GARCÍA}

Jesús: "Como el Padre me ha enviado, así también os envío yo a vosotros" (Jn 20,21). La madurez de toda vocación consiste en seguir a Jesús haciendo de la propia vida un don, como Él anticipó en la Última Cena, consumó en la cruz y se actualiza en cada Eucaristía. El pan consagrado es su "Cuerpo entregado" y el vino eucaristizado es su "Sangre derramada"... por todos nosotros, por toda la humanidad desde el inicio de la historia hasta el fin del mundo. Este es el misterio redentor actualizado en la Eucaristía. Participar de la Eucaristía, comulgar los dones eucarísticos que son presencia real del mismo Cristo, significa estar dispuestos a hacer de la propia existencia una vocación de entrega oblativa como la de Cristo, ser también "cuerpo entregado" y "sangre derramada" por los demás.

Con estos tres sacramentos no sólo se culmina el proceso sacramental de la iniciación, sino que se ponen los fundamentos de toda la vida cristiana, que tiene cierta analogía con el origen, el crecimiento y el sustento de la vida natural. "En efecto, los fieles renacidos en el Bautismo se fortalecen con el sacramentos de la Confirmación y finalmente, son alimentados en la Eucaristía con el manjar de la vida eterna, reciben cada vez con mayor abundancia los tesoros de la vida divina y avanzan hacia la perfección de la caridad". ${ }^{12}$ Así se sintetizan magistralmente en el Prefacio de la Confirmación los aspectos esenciales de la iniciación sacramental y vocacional a la vida de todo cristiano: Tú, en el Bautismo, das nueva vida a los creyentes y los haces partícipes del misterio pascual de tu Hijo. Tú los confirmas con el sello de tu Espíritu, mediante la imposición de manos y la unción real del crisma. Así, renovados a imagen de Cristo, el ungido por el Espíritu Santo y enviado para anunciar la buena nueva de la salvación, los haces tus comensales en el banquete eucarístico y testigos de la fe en la Iglesia y en el mundo.

\section{La Eucaristía en la vocación y en el proceso de formación para el ministerio sacerdotal}

Si la Eucaristía es culmen de la iniciación cristiana y elemento fundante de la vocación bautismal, es también elemento esencial en las vocaciones de especial consagración en la Iglesia, particularmente en la vocación al ministerio ordenado. Por eso, tiene una relevancia especial en el proceso formativo del seminario y una significación especial en la ordenación de presbíteros y obispos.

12 CATECISMO DE LA IGLESIA CATÓLICA (=CCE), Madrid 1992, nº 1212. 


\section{SEMINARIOS - AÑO 2008 - NO 187 \\ "INICIACIÓN CRISTIANA Y PV", AURELIO GARCÍA}

\subsection{La Eucaristía en el proceso de formación al ministerio sacerdotal}

Los documentos que regulan la vida formativa de los seminarios y casas de formación insisten en considerar la Eucaristía como el centro de toda la vida comunitaria y motiva a los formadores a infundir en los alumnos el aprecio de la misa y de la adoración al Santísimo sacramento de la Eucaristía. ${ }^{13}$ Más todavía, hay que inculcar en ellos la convicción, como futuros presbíteros, de que los sacerdotes ejercen su principal oficio en el sacramento eucarístico, en el cual se realiza continuamente la obra de nuestra redención; así, mientras se unen a la acción de Cristo sacerdote, se ofrecen cada día enteramente a Dios". 14

Esta recomendación señala un doble aspecto. Por un lado, la explicación doctrinal de la teología eucarística en connivencia con la experiencia espiritual, que descubre en la Eucaristía la actualización de la obra redentora de Jesucristo, y la ofrenda de la propia vida unida a la acción sacerdotal de Cristo. Por otro lado, el cultivo de la celebración de la Eucaristía como acción que actualiza el misterio redentor de Jesucristo, y la adoración de la santísima Eucaristía como reconocimiento de la presencia del Señor en las especies eucaristizadas.

Para ello, la Instrucción In ecclesiasticam futurorum aporta una serie de normas prácticas para regular la celebración de la Eucaristía en la proceso formativo del seminario: la comunión frecuente bajo las dos especies $\left(\mathrm{n}^{\circ}\right.$

\footnotetext{
13 CONFERENCIA EPISCOPAL ESPAÑOLA, Plan de formación sacerdotal para los seminarios mayores. La formación para el ministerio presbiteral, Madrid 1996, $\mathrm{n}^{\circ}$ 77: "La Eucaristía, centro y fuente de la vida cristiana, personal y de la Iglesia, se constituye por su celebración y participación diaria, en el sustento básico de la vida espiritual del Seminario. Ha de cuidarse también en el Seminario el culto eucarístico fuera de la celebración. Quienes están llamados a representar a Cristo en la celebración de la Eucaristía deberán asimilar las actitudes íntimas que fomenta este sacramento: la gratitud, la donación de sí mismo, la caridad y el deseo de contemplación y adoración a Cristo". Ver también otros interesantes documentos que recalcan la misma idea. Dos documentos de la SAGRADA CONGREGACIÓN PARA LA EDUCACIÓN CATÓLICA, Carta circular sobre algunos aspectos más urgentes de la formación espiritual de los seminarios, Roma 1980, pp.10-14; CONGREGACIÓN PARA LOS INSTITUTOS DE VIDA CONSAGRADA Y LAS SOCIEDADES DE VIDA APOSTÓLICA, Orientaciones sobre la formación en los Institutos religiosos, Madrid 1990, $\mathrm{n}^{\circ} 78$.

14 SAGRADA CONGREGACIÓN PARA LA EDUCACIÓN CATÓLICA, Instrucción In ecclesiasticam futurorum (=IEF), Città del Vaticano 1979, $\mathrm{n}^{\circ} 22$.
} 


\section{"INICIACIÓN CRISTIANA Y PV", AURELIO GARCÍA}

24), la asistencia diaria a la misa, incluso durante el periodo de vacaciones $\left(n^{\circ} 25\right)$, la celebración diaria de la santa misa "como acto ofrecido por Cristo y por la Iglesia para la salvación de todo el mundo, aun cuando no estén a ello obligados por deberes pastorales o no participe ningún fiel" ( $n^{\circ}$ 26), la devoción hacia la Santísima Eucaristía, la oración después de la comunión, la visita al Santísimo ( $\left.n^{\circ} 27\right)$, etc. ${ }^{15}$

\subsection{La Eucaristía en el rito de la ordenación presbiteral}

La liturgia de ordenación supone algo más que una mera ceremonia. Es la culminación del proceso formativo y el inicio ministerial del sacramento recibido. Aunque podemos hablar de los tres ministerios del sacramento del Orden: obispo, presbíteros y diáconos, fijamos nuestra atención en la ordenación de presbíteros. En el iter celebrativo de esta peculiar liturgia, compuesto de gestos y textos, se expresa también la teología de la Iglesia sobre el ministerio presbiteral. Particular mención merece la Plegaria de Ordenación y los gestos explanativos subsiguientes. En todos ellos se condensa como en un embrión (in nuce) lo que el presbítero ha de desarrollar y vivir a lo largo de su ministerio (in luce). La liturgia de ordenación sintetiza, por tanto, la teología y la espiritualidad propias del presbiterado.

La Plegaria de ordenación de los presbíteros, junto con la imposición de las manos del obispo sobre la cabeza de los ordenandos, constituye el núcleo sacramental y el requisito jurídico para la validez de las ordenaciones. En ella, el Obispo ora a Dios Padre invocando el Espíritu Santo sobre los candidatos, para que, fortalecidos por este don y en cooperación con los obispos, puedan anunciar y celebrar la obra de la redención inaugurada por Cristo. En la tercera parte de esta Plegaria, el obispo suplica a Dios Padre que sean "fieles dispensadores de los misterios de Dios". Con esta expresión paulina se hace referencia al ministerio litúrgico del presbítero, que celebra los misterios de Cristo con una doble finalidad: la alabanza a Dios y la santificación del pueblo cristiano. Los sacramentos mencionados son el Bautismo, la Eucaristía, la Reconciliación y la Unción de enfermos.

Por medio del Bautismo, los hombres son incorporados al pueblo de Dios y se renueva la Iglesia. La administración del bautismo es esencial al ministerio presbiteral porque tiene como finalidad la formación del pueblo

15 IEF, n० 23 


\section{SEMINARIOS - AÑO 2008 - NO 187 "INICIACIÓN CRISTIANA Y PV", AURELIO GARCÍA}

de Dios, la edificación y continuidad de la Iglesia, tal como confirma la tradición litúrgica oriental y occidental. 16

Por medio de la Eucaristía se nutre y alimenta el Pueblo de Dios; se hace, se restablece, se fortalece la Iglesia. La Eucaristía ha sido siempre el sacramento por excelencia del ministerio presbiteral. El estudio de las fuentes litúrgicas revela que los ritos de ordenación privilegian la misión litúrgico-sacramental, tal como se comprueba también en la tradición litúrgica oriental y occidental. ${ }^{17}$ También en el rito de ordenación presbiteral de la actual liturgia romana. Tanto la unción de las manos con el santo Crisma, como la entrega del pan y del vino, están relacionados con la Eucaristía. La oración que se dice al ungir las manos especifica que el presbítero es ungido para santificar el pueblo cristiano y ofrecer el sacrificio a Dios. Es una clara alusión a la función de santificación y al sacrificio eucarístico. ${ }^{18}$ Mucho más explícita es la relación de la Eucaristía con el presbítero en la entrega del pan y del vino, único signo que el obispo entrega al neopresbítero. ${ }^{19}$ Subyace en este rito la teología antigua,

16 La traducción latina de la plegaria del Rito Maronita emplea prácticamente la misma expresión: renovet populum fidelem per lavacrum spirituale regenerationis sancti baptismatis. Enchiridion Euchologicum Fontium Liturgicorum (=EEFL), ed. E. Lodi (BEL.S 15), Roma 1979, $n^{\circ} 2977$.

17 Aparece explícitamente mencionado en las plegarias de ordenación presbiteral, ver Les Constitutions Apostoliques, ed. M. Metzger, Tome III, Livres VII et VIII (SCh 336), Paris 1987, 218: kai. ta.j u“per tou/ laou/ sou i”erougi,aj; Rito Maronita: ministret coram altari tuo sine reatu... tibique offerat sacrificia perfecta et dona spiritualia (EEFL 2977); Rito Siro-oriental: et corde puro, conscientiaque bona inserviant altaris tuo sancto (EEFL 2978-b); la Confirmatio post ordinandum presbiterum del Rito Hispano dice: Habete ergo aditum et potestatem accedere ad altare Dei (Le Liber Ordinvm en usage dans l'Église wisigothique et mozarabe d'Espagne du cinquième au onzième siècle publié pour la première fois avec une introduction, des notes, une étude sur neuf calendriers mozarabes, etc., ed. M. Férotin, Paris 1904, 55); Corpus et sanguinem filii tui inmaculata benedictione transformentur (Liber Sacramentorum Romanae Aeclesiae ordinis anni circuli (Cod. Vat. Reg. lat. 316/Paris Bibl. Nat. 7193, 41/56). Sacramentarium Gelasianum, ed. L. C. Mohlberg - L. Eizenhöfer - P. Siffrin, (Rerum Ecclesiasticarum Documenta, Series Maior, Fontes IV), Roma 31981, 148).

18 OEPD 133: Jesucristo, el Señor, a quien el Padre ungió con la fuerza del espíritu Santo, te auxilie para santificar al pueblo cristiano y para ofrecer a Dios el sacrificio. 19 La oración que acompaña la entrega del pan y del vino dice así: Recibe la ofrenda del pueblo santo para presentarla a Dios. Considera lo que realizas e imita lo que conmemoras, y conforma tu vida con el misterio de la cruz del Señor (OEPD 163). Los Praenotanda refiriéndose a la relación de este gesto con la Eucaristía afirman: este ministerio se declara más ampliamente por medio de otros signos... 


\section{"INICIACIÓN CRISTIANA Y PV", AURELIO GARCÍA}

particularmente medieval, que interpretaba la entrega de los instrumentos propios de esta función: la patena y el cáliz, como la concesión del poder de consagrar. Por medio de este signo y de la imposición de las vestiduras sacerdotales (estola al modo sacerdotal y casulla) con las que es revestido el nuevo presbítero, se acentúa el aspecto sacerdotal de su ministerio. 20

La unión entre el presbítero y la Eucaristía se manifiesta también en la celebración de la ordenación. ${ }^{21}$ El nuevo Pontifical Romano contextualiza el sacramento del Orden en la celebración eucarística para significar mejor que el ministerio se recibe y se inicia en medio de la Eucaristía, en la asamblea más representativa de la Iglesia, con el sacramento más significativo de la vida eclesial y de su misión presbiteral.22 Por el sacramento del Orden recibido se convierte en el presidente de la Eucaristía, para ofrecer sacramentalmente el sacrificio de Cristo, y unido a él, ofrecerse a sí mismo. ${ }^{23}$ Como presidente de la celebración eucarística, el presbítero representa sacramentalmente a Jesucristo, y la celebración memorial del misterio pascual de Jesucristo, exige la actitud oferente de su propia vida, como "expresión máxima de su servicio sagrado".24

Este acento eucarístico está presente también en la ordenación presbiteral bizantina. Después de la epíclesis sobre el pan y sobre el vino, el obispo

por la entrega del pan y del vino en sus manos se indica el deber de presidir la celebración Eucarística y de seguir a Cristo crucificado (OEPD 113)

20 Para conocer mejor el significado de estos ritos puede consultarse A. LAMERI, La "Traditio Instrumentorum" e delle insegne nei riti di ordinazione. Studio storicoliturgico, Roma 1998.

21 Esta idea ha sido desarrollada por el Papa Juan Pablo II: El misterio de santificación y amor, obra del espíritu Santo, por el cual el pan y el vino se convierten en el Cuerpo y la Sangre de Cristo, actúa también en la persona del ministro en el momento de la ordenación sacerdotal. Hay, pues, una reciprocidad específica entre la Eucaristía y el Sacerdocio, que se remonta hasta el Cenáculo: se trata de dos Sacramentos nacidos juntos y que están indisolublemente unidos hasta el fin del mundo. JUAN PABLO II, Carta a los sacerdotes con ocasión del Jueves Santo, Città del Vaticano 2004, $n^{\circ} 3$.

22 P. TENA, "La ordenación y el sentido del ministerio en el diálogo ecuménico", Ph 21 (1981) 223-239.

23 Numerosos documentos eclesiales subrayan el sentido sacramental del ministerio presbiteral sobre su sentido funcional; véase como ejemplo: El ministerio ordenado, que nunca puede reducirse al aspecto funcional, pues afecta al ámbito del "ser", faculta al presbítero para actuar in persona Christi y culmina en el momento en que consagra el pan y el vino, repitiendo los gestos y las palabras de Jesús en la Última Cena.

24 M. THURIAN, La identidad del Sacerdote, Madrid 1996, 82-85; A. VANHOYE, 


\section{SEMINARIOS - AÑO 2008 - NO 187 \\ "INICIACIÓN CRISTIANA Y PV", AURELIO GARCÍA}

entrega en las manos del neopresbítero una parte del pan eucaristizado, acompañando este gesto con las siguientes palabras: Recibe esta prenda y consérvala hasta la llegada de nuestro Señor Jesucristo por quien te será reclamado. El presbítero lo conserva en sus manos hasta el momento de la comunión; significando con ello que es depositario y custodio de este sacramento hasta el final de su vida.

La teología litúrgica del ministerio presbiteral subraya su dimensión eucarística. El presbítero, como pastor de la comunidad cristiana, cuyo centro y quicio es la Eucaristía, ha de cuidar de este sacramento esencial de la vida cristiana. La pastoral vocacional no puede obviar este acento del ministerio presbiteral y de todo ministerio ordenado. La comprensión, participación y vivencia de la Eucaristía define no sólo la vocación cristiana, sino la vocación ministerial en la Iglesia.

\section{Conclusión: la mutua implicación entre Eucaristía y pastoral vocacional}

Generalmente relacionamos la expresión "pastoral vocacional" con la actividad de la Iglesia tendente a descubrir y madurar la llamada que hace el Señor a sus fieles para consagrarse en un ministerio eclesial o en un carisma específico al servicio de la Iglesia y del mundo. Entendida así podría pensarse que es utilizada en un sentido restrictivo, porque todo cristiano está llamado a una vocación bien sea en la vida ministerial, en la vida religiosa o en la vida laical. Ahondando en esta idea se podría hablar de una "pastoral vocacional bautismal"25, que ayudaría a descubrir el

\footnotetext{
"Sacramentalidad del ministerio", en COMISIÓN EPISCOPAL DEL CLERO, Espiritualidad del Presbitero Diocesano Secular. Simposio, Madrid 1987, 83-85; PDV 26; Congar concluye uno de sus artículos sobre el sacramento del Orden insistiendo en la centralidad de la Eucaristía en el ministerio presbiteral. Y. M. CONGAR, "Note sur une valeur des termes ordinare, ordinatio", RSR 58 (1984) 14: Les recherches actuelles sur le ministère ordonné, celui des prêtres, ont insisté sur son rapport à la communauté au point qu'on a pu écrire que le prêtre préside à l'Eucharistie "parce qu'il" préside la communauté.

25 Máxime cuando la gran mayoría de los cristianos no tiene experiencia de haber sido llamados, de haber recibido el don de la Vida, en el Bautismo. Como vemos la pastoral vocacional se encuentra con la inexperiencia del sacramento bautismal y eso hace necesario articular un ambiente, una cultura vocacional, donde todo cristiano conozca y experimente los valores vocacionales de la llamada, de la aceptación del don y la gratuidad, de la respuesta confiada, del agradecimiento, etc.
} 


\section{"INICIACIÓN CRISTIANA Y PV", AURELIO GARCÍA}

sentido de la vida cristiana como respuesta a la llamada de Dios. Esta tarea es competencia del proceso formativo y sacramental que llamamos Iniciación cristiana. Pero, por otro lado, podríamos hablar de una "pastoral vocacional "de consagración, ministerial", cuando se trata de discernir y acompañar la llamada a cualquiera de los tres ministerios ordenados de la Iglesia, o "carismática", cuando se trata de discernir y acompañar la llamada a un carisma concreto de especial entrega en la vida consagrada de la Iglesia o "sacramental" cuando se consagrada el amor del hombre y la mujer signo de la entrega esponsal de Cristo a su Iglesia. Es tarea de la Iglesia acompañar esos momentos "vocacionales" de la vida de un cristiano. $Y$ en ellos ocupa un lugar central la espiritualidad eucarística.

\subsection{El sentido vocacional de la pastoral eucarística}

"La pastoral vocacional es, hoy, la vocación de la pastoral. En tal sentido se puede muy bien decir que se debe " vocacionalizar " toda la pastoral o actuar de modo que toda expresión de la pastoral manifieste de manera clara e inequívoca un proyecto o un don de Dios hecho a la persona, y suscite en la misma una voluntad de respuesta y de compromiso personal." Esta elocuente afirmación pertenece al Documento final del Congreso Europeo sobre las vocaciones al sacerdocio y a la vida consagrada en Europa celebrado en Roma en 1997 y preparado conjuntamente por las Congregaciones para la Educación Católica, para las Iglesias Orientales, para los Institutos de Vida Consagrada y las Sociedades de Vida Apostólica, que lleva por título: Nuevas vocaciones para una nueva Europa. 26

Plantea que la pastoral vocacional no es una tarea aislada en la magna misión de la Iglesia, sino que constituye la nota distintiva de toda la pastoral eclesial; me atrevería a añadir que la pastoral vocacional es la vocación de todo pastor, que ha de discernir y cuidar todas las vocaciones de la comunidad cristiana: la consagración religiosa en la vida monástica y en la vida apostólica, la vocación laical, el carisma de los Institutos seculares, las Sociedades de vida apostólica, la vocación al matrimonio, las diversas formas de agregaciones-asociaciones a Institutos religiosos, las asociaciones misioneras, las nuevas formas de vida consagrada. Todas ellas son dones del Espíritu, por eso, el pastor que preside y sirve a una comunidad acoge y ayuda a cada vocación. Él ministerio ordenado es

26 OBRA PONTIFICIA PARA LAS VOCACIONES ECLESIÁSTICAS, Nuevas vocaciones para una nueva Europa, Roma 1998, nº 26. 


\section{SEMINARIOS - AÑO 2008 - NO 187 \\ "INICIACIÓN CRISTIANA Y PV", AURELIO GARCÍA}

principio de unidad y comunión entre todas las vocaciones que enriquecen la Iglesia. Y este servicio de comunión en la comunidad se manifiesta visible y sacramentalmente en la celebración de la Eucaristía que es misterio de comunión con Cristo y con la Iglesia. La celebración de la Eucaristía recuerda al presidente que es principio de comunión de todos los dones y carismas de la comunidad eclesial; que tiene la tarea de promover y cuidar toda vocación; y que es ordenado para todas las vocaciones. Quien preside la Eucaristía no puede hacer exclusiones. Su vocación de servicio abarca la catolicidad y universalidad de la Iglesia en sus variados carismas. Esta vocación de unidad y comunión es nota distintiva de quien está llamado a presidir la Eucaristía, haciendo las veces del Señor.

Él es quien convoca a la comunidad cristiana en asamblea litúrgica, quien asegura que están congregados en el nombre del Señor y en comunión de fe con la Iglesia. Él es quien, al final de de toda celebración litúrgica, envía a los presentes en nombre de Jesucristo para ser sus testigos y revivir el misterio eucarístico celebrado en la vida diaria. El ministerio pastoral de la presidencia eucarística recuerda siempre a los presentes el sentido vocacional de toda Eucaristía, que quiere ser siempre respuesta de amor al misterio del Cristo entregado por nosotros, actualizado en la celebración eucarística y vivido por los fieles en su propia vocación y misión.

\subsection{El sentido eucarístico de la pastoral vocacional.}

Tanto la primitiva predicación apostólica como la instrucción catequética de la Iglesia a lo largo de su historia puso de relieve la centralidad del misterio pascual en la vida cristiana: anunciar y vivir el misterio de Cristo muerto y resucitado. En la Eucaristía, la Iglesia actualiza el misterio pascual de Jesucristo y contempla el misterio de su amor y entrega: Cuerpo entregado... y Sangre derramada... para la salvación del mundo. Ya hemos dicho que quien comulga el "Cuerpo entregado" y la "Sangre derramada" de Jesucristo es para ser, al igual que él, "cuerpo entregado" y "sangre derramada" por todos. La Eucaristía llama al creyente a conformarse a Cristo, a vivir como Cristo, a entregarse como Cristo para dar vida al mundo: "el que come mi carne y bebe mi sangre vive en mí y yo en él". La Eucaristía se convierte así en origen de toda vocación cristiana y en ejemplo de toda respuesta vocacional. Aquel que participa de la Eucaristía está dispuesto a "hacer memoria" de Cristo y responder como Él a la llamada que le hace Dios Padre para entregarse en misión de amor. Quien participa de la Eucaristía ha de estar dispuesto a entregar la vida como Cristo. 


\section{"INICIACIÓN CRISTIANA Y PV", AURELIO GARCÍA}

También quien preside este augusto sacramento, es decir, el sacerdote, el pastor. La Eucaristía que preside se convierte en exigencia existencial para vivir su propia vocación ministerial en actitud oblativa de entrega a Cristo para el servicio de los demás. El sentido eucarístico de la vocación ministerial, no se explica solamente en categorías sociales de solidaridad humana, al modo de una actividad asistencial o un entretenimiento filantrópico; se trata de una entrega sacramental, porque quien preside actúa in persona Christi Capitis et in nomine Ecclesiae. No es únicamente él; en él actúa Cristo y la Iglesia. Él no es el protagonista, sino que es Cristo quien continúa prolongando sacramentalmente sus signos salvadores a través del presbítero para ofrecer su salvación a la humanidad de todos los tiempos. El ministerio sacerdotal es una proexistencia, una Eucaristía existencial continuada en su misión pastoral que parte y tiende siempre hacia la celebración litúrgica de la Eucaristía. ${ }^{27}$

La pastoral vocacional, máxime la dedicada al ministerio ordenado, ha de presentar la Eucaristía como la mejor escuela y ejemplo donde aprender la actitud y respuesta adecuadas a tan magnífico don de Dios. Cada Eucaristía es una llamada vocacional, un acontecimiento vocacional para quien participa en ella. Y en el misterio de Cristo actualizado en la misa se encuentra la respuesta existencial de todo cristiano: entregar la vida gozosa y gratuitamente con Cristo para la salvación del mundo.

27 A. GARCÍA MACÍAS, "La presidencia litúrgica del ministerio ordenado", en J. M. DE MIGUEL GONZÁLEZ (dir.), El ministerio presbiteral. Retos y tareas. Colegiata de San Isidoro. León, 24-26 de septiembre de 2007, Salamanca 2008, 205-223; A. CRESPO HIDALGO, "La Caridad Pastoral informa otras virtudes del Pastor", en COMISIÓN EPISCOPAL DEL CLERO, Eucaristía y caridad pastoral. Año Jubilar 2000, Madrid 2000, 110. 